\title{
Adsorptive removal of strontium(II) using macroporous poly(AGE-co-EGDMA) beads modified with resorcin[4]arene
}

\author{
K MULANI ${ }^{1}$, V PATIL ${ }^{2}$, N CHAVAN ${ }^{3}$ and K DONDE ${ }^{1, *}$ \\ ${ }^{1}$ Department of Chemistry, Ramnarain Ruia College, Matunga (E), Mumbai 400019, India \\ ${ }^{2}$ Department of Chemistry, University of Mumbai, Vidyanagari, Santacruz (E), Mumbai 400098, India \\ ${ }^{3}$ Polymer Science and Engineering Division, CSIR-National Chemical Laboratory, Pune 411008, India \\ *Author for correspondence (nitudonde@yahoo.co.in)
}

MS received 10 March 2018; accepted 24 October 2018; published online 9 March 2019

\begin{abstract}
Adsorption behaviour of strontium(II) on macroporous poly(allyl glycidyl methacrylate-co-ethylene glycol dimethacrylate) [poly(AGE-co-EGDMA)] beads modified with resorcin[4]arene was studied using macroporous crosslinked [poly(AGE-co-EGDMA)] beads. The macroporous crosslinked [poly(AGE-co-EGDMA)] beads were synthesized by suspension polymerization techniques, followed by functionalization with amino derivatives of resorcin[4]arene. The poly(AGE-co-EGDMA) beads were characterized by FTIR, ${ }^{1} \mathrm{H}$ and ${ }^{13} \mathrm{C}-\mathrm{NMR}$, elemental analysis and particle-size analysis . The surface morphology of beads was studied by scanning electron microscopy. The functionalized poly(AGE-co-EGDMA) beads were used as adsorbents for strontium removal. The crucial factors including the effect of $\mathrm{pH}$, time, initial concentration of metal ions and adsorbent dose were investigated to optimize the maximum adsorption efficiency of $\mathrm{Sr}$ (II). The equilibrium data of strontium(II) ions adsorbed on functionalized poly(AGE-co-EGDMA) beads were analysed by pseudo-first- and pseudo-second-order kinetic models. The pseudo-second-order kinetic model indicated that strontium was adsorbed by chemisorption.
\end{abstract}

Keywords. AGE-EGDMA beads; resorcin[4]arene; Sr(II); adsorption.

\section{Introduction}

Presence of toxic metals in ground water sources is an important issue in water and wastewater treatments, which affects human health. It is surprising that nature has been a large producer of radioactive waste. Small amounts of radioactive materials are contained in mineral springs, sand mounds and volcanic eruptions. These are referred as naturally occurring radioactive materials (NORMs) and nuclear waste generated from nuclear reactors.

Nowadays, strontium is readily used in electronic industries because it improves brilliance of glass and the quality of picture. In the human body, teeth and bones were found to have the highest concentration of strontium. The most common health effects of radioactive ${ }^{90} \mathrm{Sr}$ include bone pain, bone fractures, bone disorders and bone cancer [1]. Since ${ }^{90} \mathrm{Sr}$ is considered to be one of the most hazardous elements in the fission product, it is necessary to remove it from the waste stream before being discharged to the environment.

There are several methods and technologies available for waste-water treatment. But unfortunately, not all processes and technologies are environmentally, economically and socially sustainable. The four major classes of chemical separation techniques of heavy metal recovery from waste water include chemical precipitation, solvent extraction, electrolytic recovery and adsorption/ion exchange.
Adsorption is one of the most efficient and advanced waste-water treatment methods that has been extensively used. Research on adsorption of strontium from drinking water has been explored. Adsorption is the most preferred method for the removal of strontium due to its low cost, versatility, economical effectiveness and simple usage. In the adsorption process, a substrate (adsorbate) is adsorbed on the adsorbing material (adsorbent). The most common adsorbent efficiently used for the treatment of waste water includes activated carbon, clay, minerals, bio-adsorbents, like algae, fungi, bacteria and yeast, and low cost adsorbents/agricultural waste [2-5].

Recently polymeric beads prepared by suspension polymerization techniques have extensively been used for metalion recovery due to their high surface area, porosity, mechanical and thermal stabilities. Due to their stability in a range of buffers from $\mathrm{pH} 1$ to 11, acrylic-based resins are efficiently used as adsorbents for the removal of different metal ions [6]. However, microspheres have a higher packing density than the bulk material, and hence, hyper cross-linked polystyrene microspheres have been widely used as packing materials, adsorbents, templates for nanoparticle growth and ion exchange resins [7]. Zhou et al [8] systematically synthesized conjugated microporous polymers of tunable pore size distribution using different types of monomers. The functional polymers, like poly(vinyl pyridine-ethylene 
glycol methacrylate-ethylene glycol dimethacrylate), have been synthesized and used for the removal of several metals [9]. Kurczewska and Schroeder [10] developed a novel complexing agent by modification of epoxy-based resin with a chelating agent i.e., amines for adsorption of metal ions from aqueous solutions.

In recent years, allyl glycidyl ether (AGE)-based macroporous cross-linked polymeric beads have attracted great interest because of their chemical and structural versatilities. The epoxy groups present in the AGE polymers can rapidly react with various reagents like amines, alcohols and thiols yielding a specific adsorbent with high capacity and good selectivity [11]. In this work, we report the synthesis of polymeric beads by suspension polymerization of AGE and ethylene glycol dimethacrylate (EGDMA). The functionalization of AGE-EGDMA beads was carried out using amino resorcin[4] arene. The resulting polymeric beads were used to study the adsorption capacity towards strontium metal.

\section{Experimental}

\subsection{Materials}

Analytical grade AGE and EGDMA were procured from Sigma-Aldrich, USA. Resorcinol, strontium nitrate, arsenazo(III), sodium citrate and sorbitan monooleate (Span 80) were purchased from Loba Chemie, Mumbai, India. Formaldehyde (37\% solution) was received from Qualigens, India. Sulphuric acid (95-98\%) and nitric acid (70\%) were procured from Merck, India. The protecting colloid polyvinyl pyrrolidone (PVP, Mw 3,60,000 $\mathrm{g} \mathrm{mol}^{-1}$ ) was obtained from Fluka Germany.

\subsection{Preparation of polymeric beads}

Polymeric beads (AGE-EGDMA) were prepared by copolymerization of AGE and EGDMA monomers by suspension polymerization techniques. The monomer composition is shown in table 1 . The suspension polymerization was carried out in a double-walled cylindrical reactor with a diameter of $11 \mathrm{~cm}$ and a height of $15 \mathrm{~cm}$. The continuous phase was prepared by dissolving $1 \%$ polyvinyl pyrrolidone in $100 \mathrm{ml}$ of deionized water. The organic phase consisted of monomer AGE, crosslinker EGDMA, initiator AIBN and pore-forming agent, cyclohexanol. The organic phase was slowly added to the aqueous phase with a stirring speed of $300 \mathrm{rpm}$ under a nitrogen atmosphere. After completion of addition, temperature was raised up to $70^{\circ} \mathrm{C}$ and polymerization was continued for $3 \mathrm{~h}$.

The polymeric beads obtained were then thoroughly washed with water, methanol and acetone and dried overnight at $60^{\circ} \mathrm{C}$ under vacuum. Furthermore, polymeric beads were purified by the Soxhlet extraction method in which methanol was used as the extracting solvent. The scheme for the
Table 1. Monomer composition for the preparation of polymeric beads.

\begin{tabular}{lccc}
\hline Polymer code & AGE in $(\mathrm{mol})$ & EGDMA in $(\mathrm{mol})$ & CLD, \% \\
\hline AE-25 & $6.278(0.0550)$ & $2.616(0.0132)$ & 25 \\
AE-50 & $4.817(0.0422)$ & $4.202(0.0212)$ & 50 \\
AE-75 & $3.949(0.0346)$ & $5.035(0.0254)$ & 75 \\
AE-100 & $3.344(0.0293)$ & $5.807(0.0293)$ & 100 \\
AE-150 & $2.556(0.0224)$ & $6.660(0.0336)$ & 150 \\
AE-200 & $2.066(0.0181)$ & $7.195(0.0363)$ & 200 \\
\hline
\end{tabular}

Monomer (O) phase: Monomer (AGE) + cross-linker(EGDMA) + Span $80=$ $1.6 \mathrm{~g}, \mathrm{AIBN}=0.2 \mathrm{~g}$, outer aqueous $\left(\mathrm{W}_{2}\right)$ phase: water $=100 \mathrm{ml}+\mathrm{PVP}=1 \mathrm{~g}$, porogen $=$ cyclohexanol, monomer to porogen ratio 1:1.6, stirring speed during polymerization $=300 \mathrm{rpm}$, polymerization temperature $=70^{\circ} \mathrm{C}$, time $=3 \mathrm{~h}$.

synthesis of polymeric beads of AGE-EGDMA is depicted in scheme 1 .

\subsection{Synthesis of resorcin[4]arene}

Resorcin[4] arene was synthesized according to a well-known procedure [12]. In a $100 \mathrm{ml}$ two-necked round-bottom flask equipped with a reflux condenser and dropping funnel, $11 \mathrm{~g}$ $(0.1 \mathrm{~mol})$ of resorcinol and $12.6 \mathrm{ml}(0.1 \mathrm{~mol})$ of $35 \%$ acetaldehyde were added. The mixture was stirred for $15 \mathrm{~min}$ at $10^{\circ} \mathrm{C}$. To the above reaction mixture, concentrated hydrochloric acid was carefully added with the help of a dropping funnel. The precipitate was rapidly formed. The reaction mixture was further stirred at $75^{\circ} \mathrm{C}$ for $1 \mathrm{~h}$, cooled in an ice bath and filtered, and then washed with water. It was then recrystallized using ethanol:water (30:70) to obtain yellow coloured crystals of resorcin[4]arene. The synthesis of resorcin[4]arene and its amino derivatives are presented in scheme 2.

\subsection{Aminomethylation of resorcin[4]arene}

To a solution of $1 \mathrm{~g}(1.8 \mathrm{mmol})$ of resorcin[4]arene and $10 \mathrm{ml}$ of ethanol:DCM (50:50), $360 \mu \mathrm{l}(2.29 \mathrm{mmol})$ of formaldehyde and $240 \mu \mathrm{l}(4.5 \mathrm{mmol})$ of ethylene diamine were added. The solution was stirred at room temperature for $12 \mathrm{~h}$ under a nitrogen atmosphere. Reaction progress was monitored by TLC in ethylacetate:chloroform (50:50). The product obtained was filtered and washed with methanol and dried at $60^{\circ} \mathrm{C}$ for $4 \mathrm{~h} \mathrm{[13].}$

\subsection{Post-modification of AGE-EGDMA beads with amino resorcin[4]arene}

In the reaction flask containing a mixture of 1,4-dioxane and deionized water $(1: 1 \mathrm{v} / \mathrm{v}), 2 \mathrm{~g}$ of AGE-EGDMA beads were added. To the above reaction mixture, sodium hydroxide and amino-methylated resorcin[4]arene were added. The reaction mixture was then refluxed at $80^{\circ} \mathrm{C}$ for $12 \mathrm{~h}$. The resulting product was filtered and washed repeatedly with 


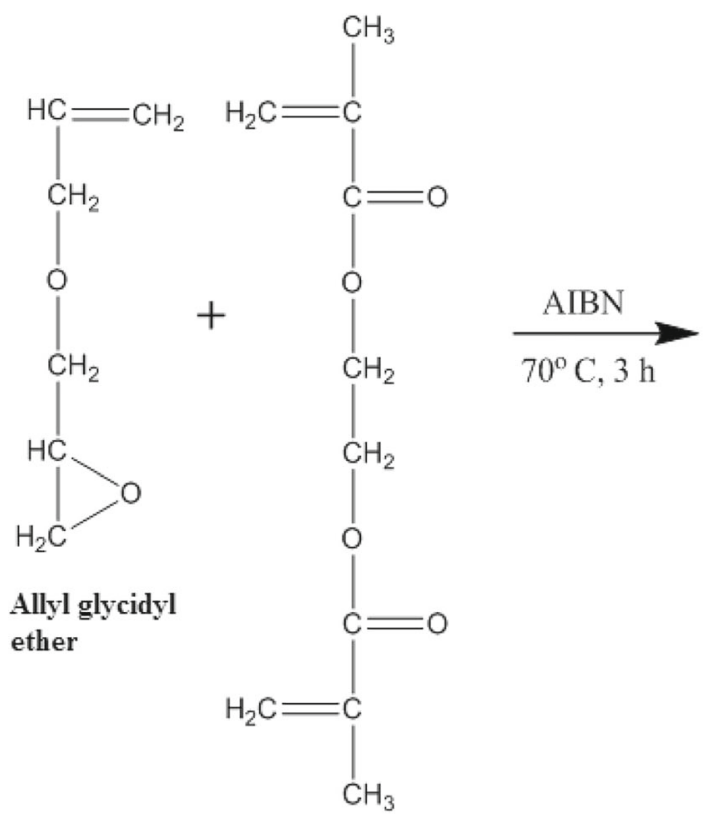

Ethylene glycol dimethacrylate

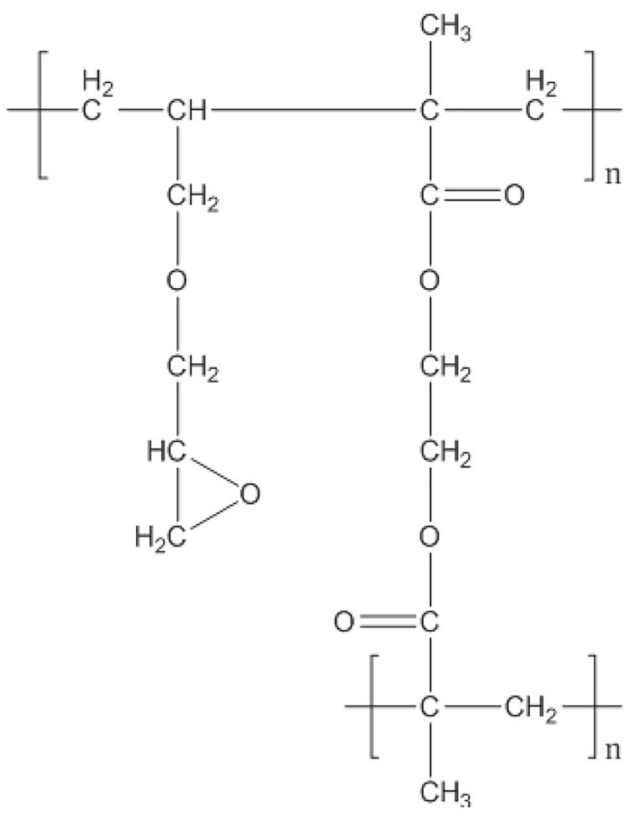

poly(AGE-co-EGDMA)

Scheme 1. Preparation of AGE-EGDMA polymeric beads by the suspension polymerization of poly(AGEco-EGDMA).

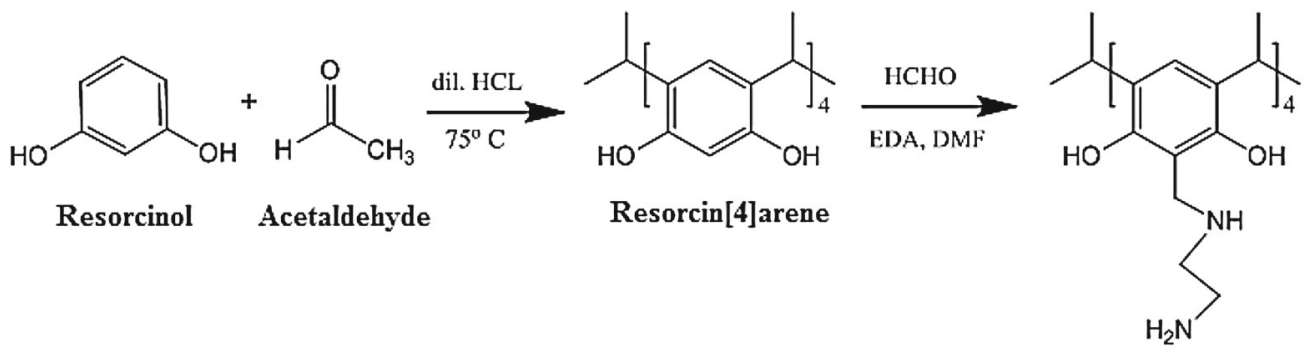

AM-Resorcin[4] arene

Scheme 2. Synthesis of resorcin[4]arene and its amino derivatives (AM-resorcin[4]arene).

distilled water. Finally, modified AGE-EGDMA beads were dried in a vacuum oven at $60^{\circ} \mathrm{C}$. The post-modification of AGE-co-EGDMA is presented in scheme 3.

\section{Results and discussion}

\subsection{Determination of epoxy number}

Ten millilitres of methanolic $\mathrm{KOH}$ was pipetted and titrated against standard $0.1 \mathrm{~N}$ KHP solution using phenolphthalein as an indicator. The end point is pink to colourless.

For the blank titration, $25 \mathrm{ml}$ of pure 1,4-dioxane and $25 \mathrm{ml}$ of $0.2 \mathrm{~N} \mathrm{HCl}$ in dioxane solution were added in a conical flask and the solution was refluxed for 1,3 and $6 \mathrm{~h}$ at $100-105^{\circ} \mathrm{C}$. Then, flask was cooled to room temperature and $25 \mathrm{ml}$ of neutral cresol-red indicator was added. The reaction mixture was titrated against $0.1 \mathrm{~N}$ methanolic $\mathrm{KOH}$. The end point is faint pink to violet.

The blank titration was carried out by weighing accurately $0.1 \mathrm{~g}$ of sample in a conical flask. To this conical flask, $25 \mathrm{ml}$ of pure 1,4-dioxane and $25 \mathrm{ml}$ of $0.2 \mathrm{~N} \mathrm{HCl}$ in dioxane solution were added and the solution was refluxed for 1,3 and $6 \mathrm{~h}$ at $100-105^{\circ} \mathrm{C}$. Then, the flask was cooled to room temperature and $25 \mathrm{ml}$ of neutral cresol-red indicator was added. The reaction mixture was titrated against $0.1 \mathrm{~N}$ methanolic $\mathrm{KOH}$. The end point is faint pink to violet.

$$
\text { Epoxy content }=\frac{(B-V) \times N}{10 \times W},
$$

where $B$ the volume $(\mathrm{ml})$ of $\mathrm{KOH}$ standard aqueous solution consumed by $\mathrm{HCl}$-dioxane solution with no dissolved 


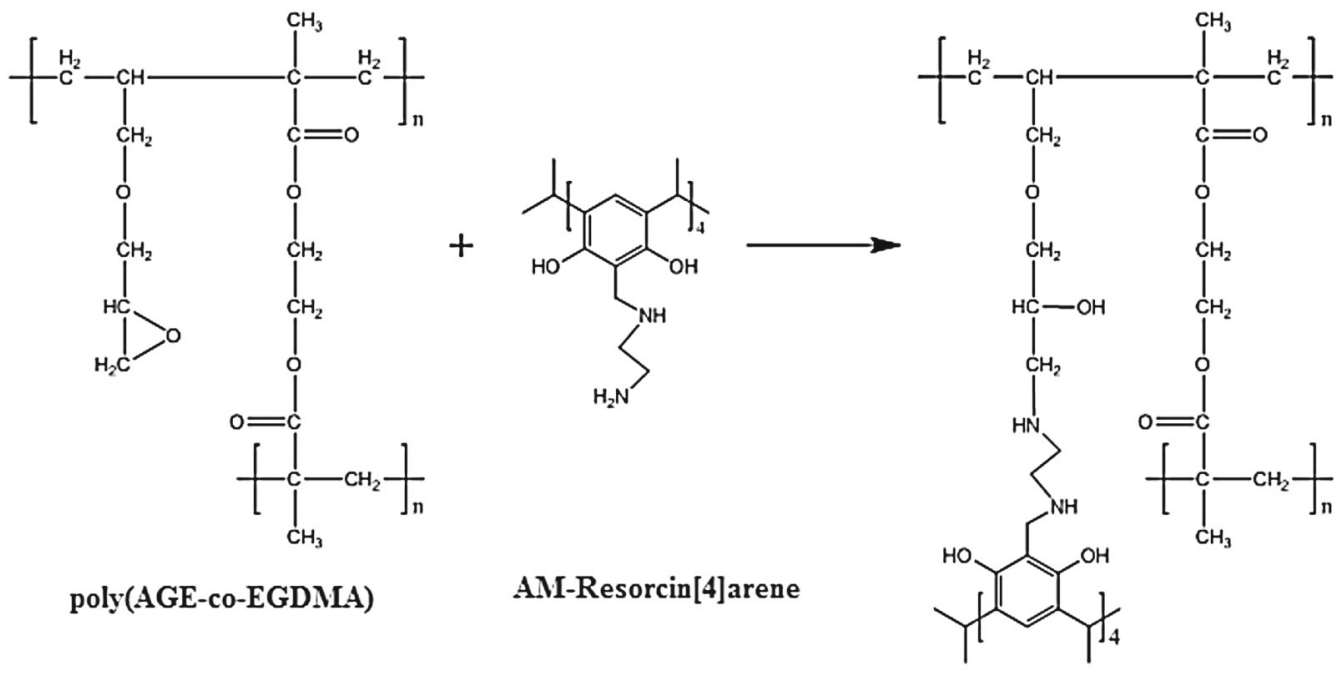

CM-poly(AGE-co-EGDMA)

Scheme 3. Chemical modification of AGE-co-EGDMA beads with AM-resorcin[4]arene (CM-poly(AGEco-EGDMA).

Table 2. Epoxy content of AGE-EGDMA polymers.

\begin{tabular}{lcccccc}
\hline Polymer code & AE-25 & AE-50 & AE-75 & AE-100 & AE-150 & AE-200 \\
\hline Epoxy content $\left(\mathrm{mmol} \mathrm{g}^{-1}\right)$ & 4.76 & 3.98 & 2.86 & 2.67 & 2.08 & 1.18 \\
\hline
\end{tabular}

sample, $V$ the volume $(\mathrm{ml})$ of $\mathrm{KOH}$ standard aqueous solution consumed by $\mathrm{HCl}$-dioxane solution with dissolved sample, $N$ the normality of $\mathrm{KOH}$ and $W$ the mass (g) of the sample.

To estimate the availability of surface epoxy groups, wet reactive epoxy titration was carried out. The epoxy content of AGE-EGDMA polymeric beads is summarized in table 2. The results show that epoxy content gradually decreases as cross-link density increases. Also, surface tension of AGE in contact with water is comparatively lower than that of EGDMA. Therefore, AGE molecules will tend to migrate towards the surface of droplets.

\subsection{NMR spectroscopy}

The ${ }^{1} \mathrm{H}$ and ${ }^{13} \mathrm{C}-\mathrm{NMR}$ spectra of the resorcin[4]arene are shown in figures 1 and 2, respectively. The ${ }^{1} \mathrm{H}$ spectrum was recorded at $200 \mathrm{MHz}$ in acetone- $\mathrm{d}_{6}$ in the range of 0-14 ppm using tetramethylsilane as an internal standard.

The ${ }^{1} \mathrm{H}$ spectrum was recorded at $200 \mathrm{MHz}$ in acetone- $\mathrm{d}_{6}$ as shown in figure 1 . Predominant sharp peaks are observed at $\delta 1.75 \mathrm{ppm}\left(-\mathrm{CH}_{3}\right), \delta 4.5 \mathrm{ppm}(-\mathrm{CH}-), \delta 6.23 \mathrm{ppm}(\mathrm{Ar}-\mathrm{H})$, $\delta 7.66$ and $8.68 \mathrm{ppm}(\mathrm{Ar}-\mathrm{OH})$ [14].

The ${ }^{13} \mathrm{C}$ spectrum was recorded at $200 \mathrm{MHz}$ in acetone- $\mathrm{d}_{6}$ as depicted in figure 2. The sharp peaks are observed at $\delta$ 20.5 ppm $\left(-\mathrm{CH}_{3}\right), \delta 103.8$ ppm $(-\mathrm{CH}-), \delta 125.4,126.4$ and $152.6 \mathrm{ppm}$ (aromatic carbon).
The ${ }^{1} \mathrm{H}$ and ${ }^{13} \mathrm{C}$-NMR spectra of the aminomethylated resorcin[4] arene are shown in figures 3 and 4, respectively, and ${ }^{13} \mathrm{C}-\mathrm{NMR}$ depth is shown in figure 5 .

The ${ }^{1} \mathrm{H}-\mathrm{NMR}$ spectrum shows the predominant sharp peaks at $\delta 1.22 \mathrm{ppm}\left(-\mathrm{CH}_{2}-\right), \delta 1.70 \mathrm{ppm}\left(-\mathrm{CH}_{3}\right), \delta 3.70 \mathrm{ppm}$ $\left(\mathrm{Ar}-\mathrm{CH}_{2}-\right), \delta 4.56 \mathrm{ppm}(-\mathrm{CH}-), \delta 6.23 \mathrm{ppm}(\mathrm{Ar}-\mathrm{H})$ and $\delta$ $8.12 \mathrm{ppm}(\mathrm{Ar}-\mathrm{OH})$.

The ${ }^{13} \mathrm{C}$-NMR spectrum displayed the major peaks at $\delta$ $19.5 \mathrm{ppm}\left(-\mathrm{CH}_{3}\right), \delta 27.5 \mathrm{ppm}\left(-\mathrm{CH}_{2}-\right), \delta 44.2 \mathrm{ppm}(\mathrm{N}-$ $\left.\mathrm{CH}_{2}-\right), \delta 56.6 \mathrm{ppm}\left(\mathrm{Ar}-\mathrm{CH}_{2}-\right), \delta 107.8 \mathrm{ppm}(-\mathrm{CH}-), \delta$ 121.5 and $124.8 \mathrm{ppm}$ (aromatic carbon). In figure 5, the peak observed at $\delta 56.8 \mathrm{ppm}$ is due to the formation of a methylene bridge.

\subsection{Elemental analysis}

The elemental composition of aminomethylated resorcin[4]arene-modified AGE-EGDMA polymeric beads is shown in table 3. This study reveals that AGE-EGDMA polymeric beads were chemically modified by aminomethylated resorcin[4]arene.

\subsection{FTIR spectroscopy}

The FTIR spectra of poly(AGE-EGDMA) beads and aminomethylated resorcin[4]arene-modified poly(AGEEGDMA) beads are shown in figure 6. As seen in figure 6, the 


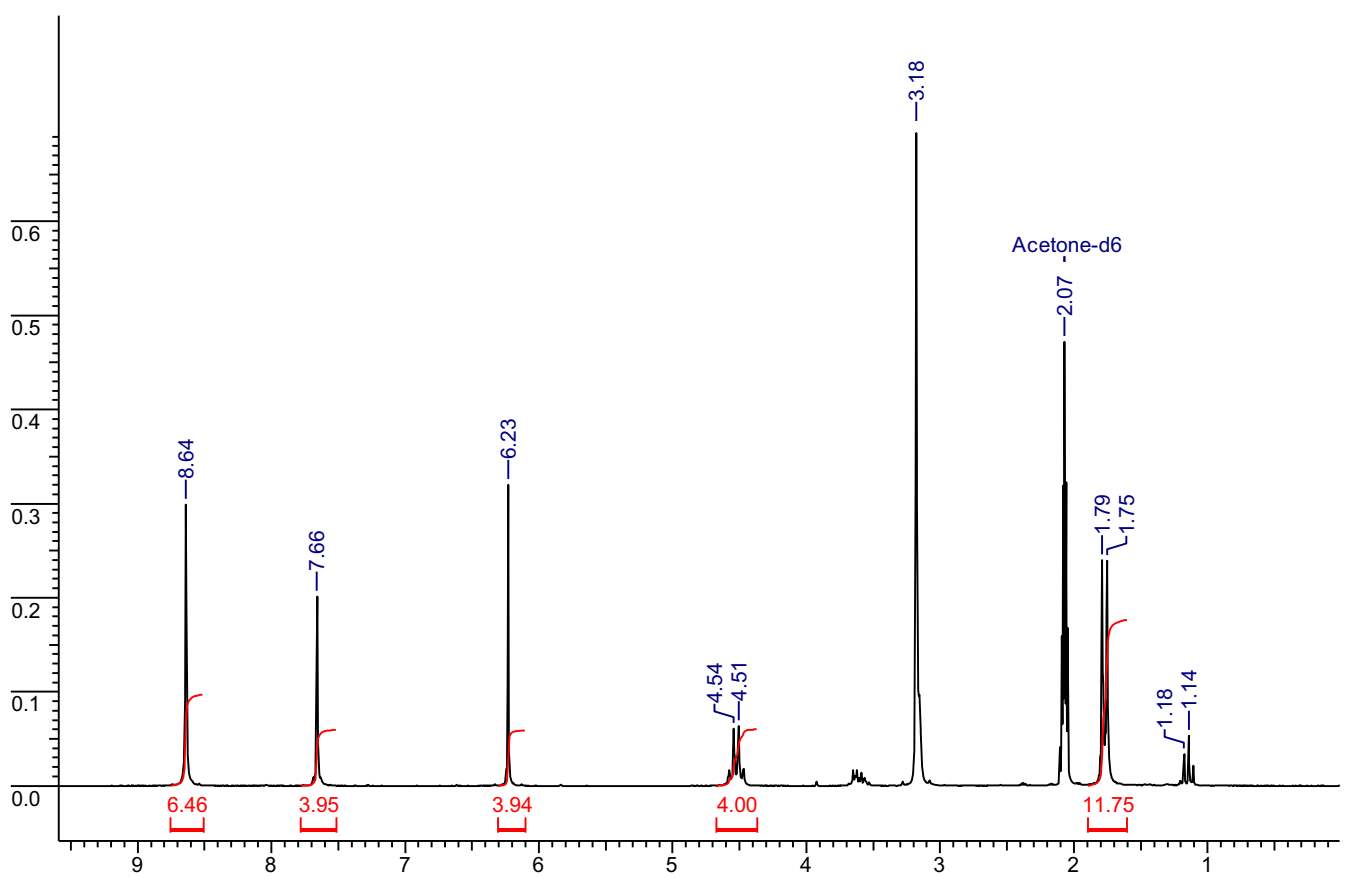

Figure 1. ${ }^{1} \mathrm{H}-\mathrm{NMR}$ resorcin[4] arene.



Figure 2. ${ }^{13} \mathrm{C}-\mathrm{NMR}$ resorcin[4]arene.

peak at $968 \mathrm{~cm}^{-1}$ indicates the epoxy group incorporated into the polymer chain. The peak observed at $2936-2991 \mathrm{~cm}^{-1}$ is assigned to the stretching vibration of the $\mathrm{C}-\mathrm{H}$ bond. The peak displayed at $1151 \mathrm{~cm}^{-1}$ is attributed to the stretching vibration of the $\mathrm{C}-\mathrm{O}$ ester bond. The peak noticed at $1730 \mathrm{~cm}^{-1}$ corresponds to the stretching vibration of the $-\mathrm{C}=\mathrm{O}$ bond.
The characteristic peaks for crosslinked AGE-EGDMA polymers were not changed in chemically modified beads, except for the intensity of the epoxy group vibration. The peaks observed at 955 and $854 \mathrm{~cm}^{-1}$ attributed to the epoxy group vibration in the IR spectrum of poly(AGEEGDMA) beads, which have not completely vanished in 




Figure 3. ${ }^{1} \mathrm{H}-\mathrm{NMR}$ of aminomethylated resorcin[4]arene.

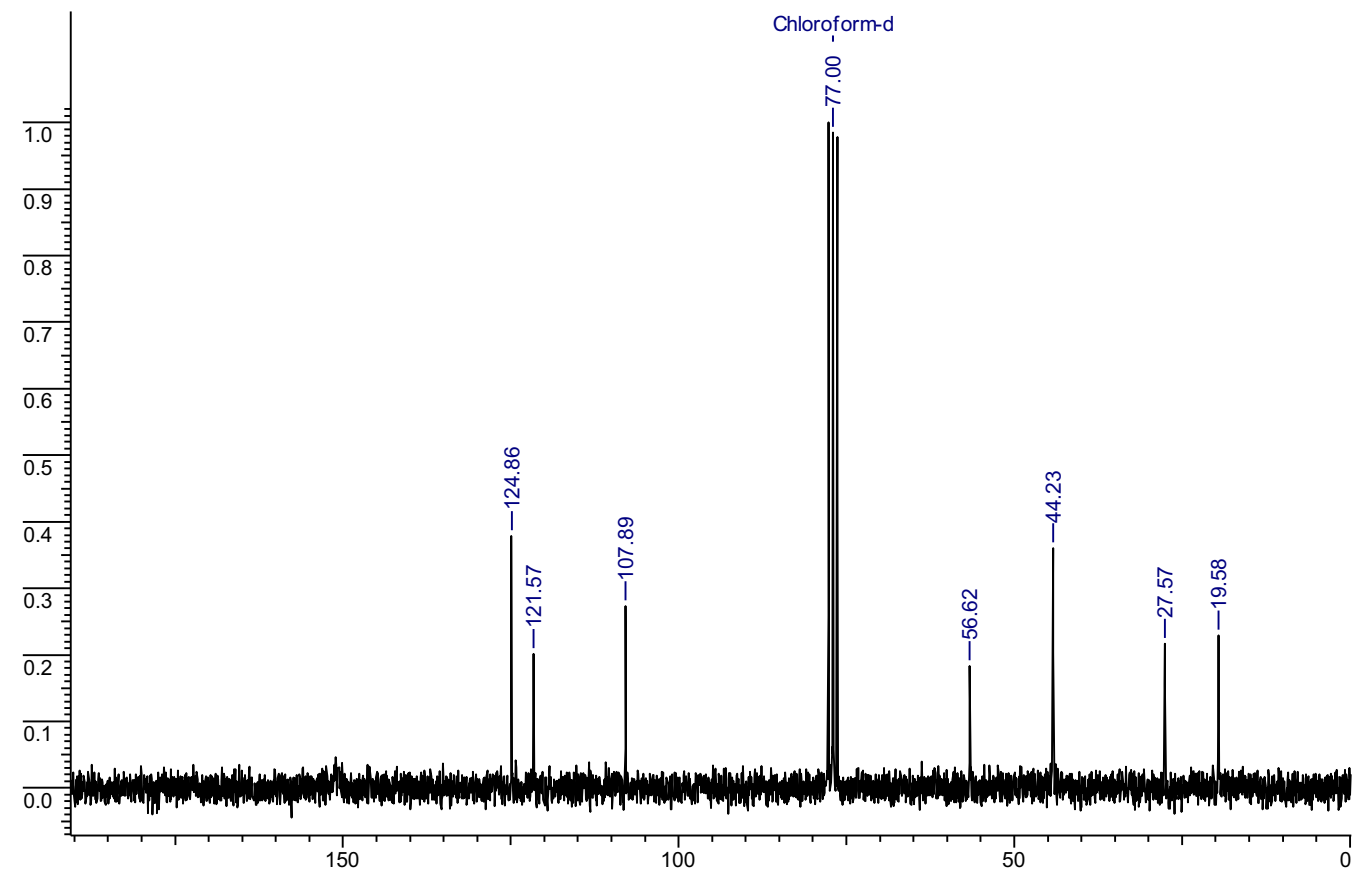

Figure 4. ${ }^{13} \mathrm{C}-\mathrm{NMR}$ of aminomethylated resorcin[4]arene.

chemically modified poly(AGE-EGDMA) beads, but their intensity became small and they were shifted to a higher frequency of $968 \mathrm{~cm}^{-1}$. The absorption peak at $3528 \mathrm{~cm}^{-1}$ is assigned to the $\mathrm{N}-\mathrm{H}$ stretching.

\subsection{Surface morphology}

The scanning electron microscopy images are used to visualize the surface morphology of the polymeric beads. The 


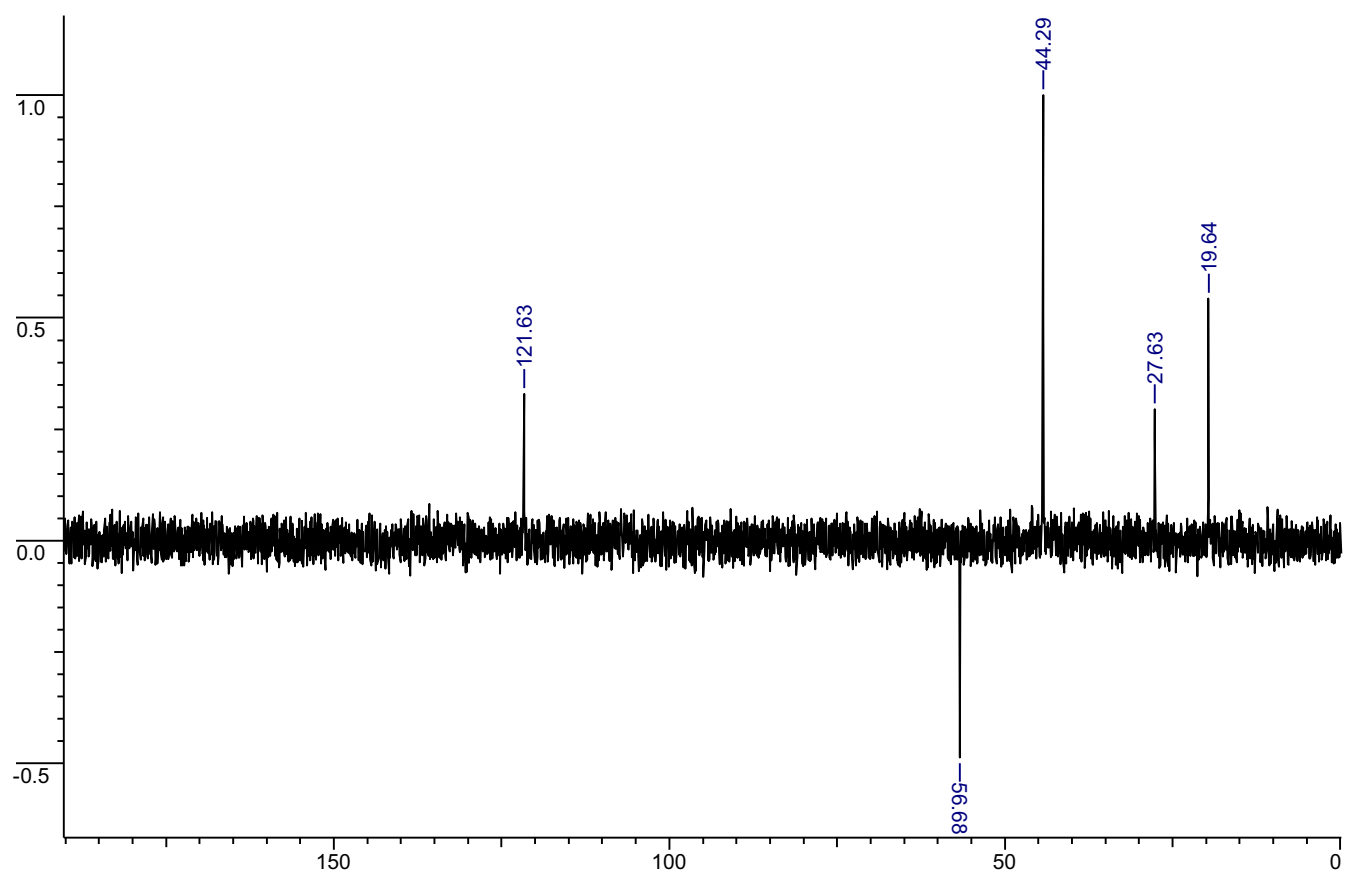

Figure 5. ${ }^{13} \mathrm{C}-\mathrm{NMR}$ of aminomethylated resorcin[4]arene (depth).

Table 3. Elemental composition of chemically modified AGEEGDMA polymers.

\begin{tabular}{llll}
\hline Polymer code & $\% \mathrm{C}$ & $\% \mathrm{H}$ & $\% \mathrm{~N}$ \\
\hline AE-25 & 56.95 & 6.94 & 0.85 \\
AE-50 & 56.76 & 6.69 & 0.49 \\
AE-75 & 56.41 & 6.34 & 0.45 \\
AE-100 & 57.39 & 6.76 & 0.42 \\
AE-150 & 56.91 & 6.32 & 0.32 \\
AE-200 & 57.06 & 6.49 & 0.23 \\
\hline
\end{tabular}

SEM images of AGE-EGDMA polymeric beads are shown in figure 7 . It clearly indicates that the beads are spherical and monodisperse.

The surface morphology and properties of polymeric beads synthesized by suspension polymerization depend on the composition of the monomeric mixture and polymerization conditions. The initiator decomposes into free radicals. These free radicals initiate the polymerization and simultaneously cross-linking reaction takes place between the monomer and cross-linker. After certain reaction time, a threedimensional network of infinitely large size may start to form beads. The surface area and pore volume of the synthesized AGE-EGDMA polymeric beads were measured by using a monosorb surface area analyser (Quantachrome Instruments, USA) and a single point Brunauer-Emmett-Teller method by measuring the adsorption of nitrogen at liquid nitrogen temperature. The experimental values obtained are presented in table 4. The surface area of AGE-EGDMA polymeric beads was in the range of $8-19 \mathrm{~m}^{2} \mathrm{~g}^{-1}$ which is relatively lower.
It may be due to water droplets or porogen droplets that are trapped during the formation of a cross-linking polymer. It also varies with the cross-link density. The pore volume of AGE-EGDMA polymeric beads was in the range of 0.033 $0.076 \mathrm{cc} \mathrm{g}^{-1}$.

\subsection{Particle size analysis}

From several decades, a suspension polymerization technique was used to synthesize micro-sized polymeric beads for adsorption purposes. The polymers were produced with different morphologies and surface areas by changing porogen. These synthesized porous polymers are widely used in water-treatement operations. The column diagram of particle size distribution and average particle size, specific surface area and pore volume of AGE-EGDMA polymeric beads is shown in figure 8 and table 4 , respectively.

\subsection{Epoxy content}

The concentration of the monomer and crosslinker (cross-link density) was determined by the following equation.

$$
A=\frac{\text { Mol. wt. of } M}{\text { Density of } M} X+\frac{\text { Mol. wt. of } C}{\text { Density of } C} X \mathrm{CLD} \text {, }
$$

where $A$ is the batch size, $M$ the monomer, $C$ the crosslinker, CLD the cross-link density and $X$ the determination factor. 



Figure 6. (A) FTIR spectrum of AGE-EGDMA beads and (B) modified AGE-EGDMA beads.

The surface epoxy content of AGE-EGDMA polymeric beads was determined by the titration method. The wetreactive epoxy titration gives rough calculation of the availability of epoxy groups present on the polymer surface.

Figure 9 depicts the value of calculated and observed surface epoxy groups at different cross-link densities. It clearly indicates that the observed epoxy content was lower than the calculated value. This may be due to the concentration of epoxy groups present at or near the surface, which react with acid during titration and is rather low. It indicates that the majority of epoxy groups were buried in the matrix. Hence, the observed epoxy value was lower compared to the calculated epoxy value. The epoxy value also decreases as cross-link density increases because the 

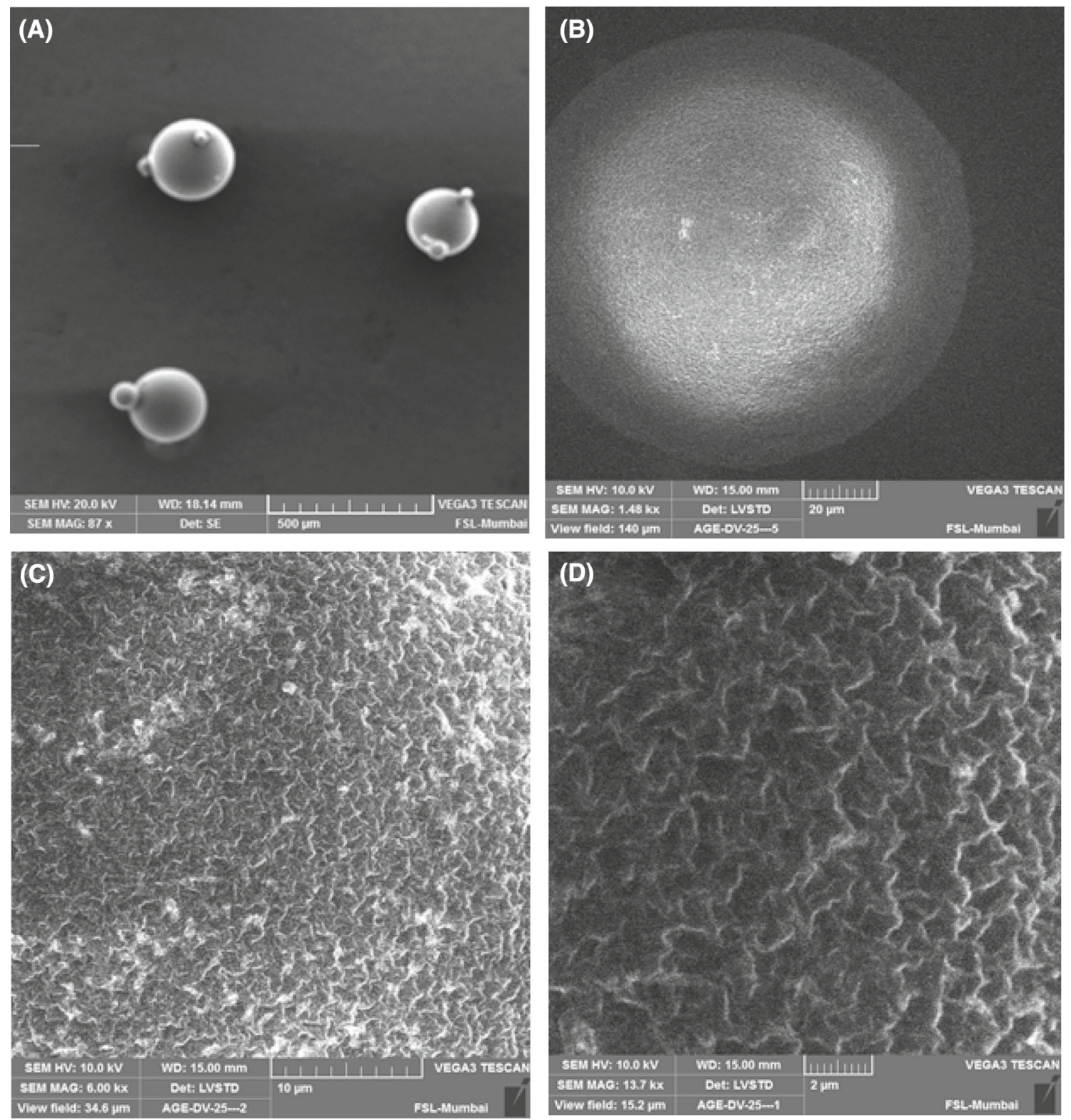

Figure 7. SEM images of AGE-EGDMA beads.

Table 4. Average particle size, specific surface area and pore volume of AGE-EGDMA polymeric beads.

\begin{tabular}{lrcc}
$\begin{array}{l}\text { Polymer } \\
\text { code }\end{array}$ & $\begin{array}{c}\text { Average particle } \\
\text { size }(\mu \mathrm{m})\end{array}$ & $\begin{array}{r}\text { Specific surface } \\
\text { area }\left(\mathrm{m}^{2} \mathrm{~g}^{-1}\right)\end{array}$ & $\begin{array}{r}\text { Pore volume } \\
\left(\mathrm{cc} \mathrm{g}^{-1}\right)\end{array}$ \\
\hline AE-25 & 89.12 & 10.72 & 0.035 \\
AE-50 & 73.55 & 19.01 & 0.076 \\
AE-75 & 73.45 & 13.66 & 0.047 \\
AE-100 & 74.30 & 8.66 & 0.036 \\
AE-150 & 88.97 & 18.21 & 0.070 \\
AE-200 & 105.42 & 13.25 & 0.033 \\
\hline
\end{tabular}

concentration of the AGE monomer decreases with an increase in cross-link density. The calculated epoxy value decreases with a decrease in AGE content in the polymer varying from 6.19 to $1.96 \mathrm{mmol} \mathrm{g}^{-1}$ (from 25 to $200 \%$ cross-link density). This is due to epoxy functionality which plays an important role in epoxidation. The epoxy values obtained by the titration method (experimental) are in the range of $4.76-1.18 \mathrm{mmol} \mathrm{g}^{-1}$ (from 25 to $200 \%$ cross-link density). The difference between these epoxy values indicated that some fraction of the epoxy group undergo ring opening reaction and some fraction of the epoxy group in the polymeric beads were buried in the matrix.

\subsection{Adsorption experiments}

The synthesized aminoresorcin[4]arene-modified AGEEGDMA polymeric beads were tested for the adsorption of strontium metal. In a sorption study, known quantity of 




Diam.(um)->

Figure 8. Column diagram of particle-size distribution of AE-25.



Figure 9. Comparison of surface epoxy contents (calculated and observed).

chemically modified AGE-EGDMA polymeric beads was gently shaken with known quantity of metal ion solution. The residual amount was spectrophotometrically analysed using the complexing agent arsenazo(III). Absorbance of the purple coloured solution was observed at $\lambda 640 \mathrm{~nm}$ against blank. All the experiments related to the adsorption study were carried out at room temperature.

The $100 \mathrm{ppm}$ concentration of strontium chloride stock solution was prepared by dissolving $243.9 \mathrm{mg}$ of strontium chloride in deionized water. From this, different concentration solutions were prepared to study the effect of concentration on metal adsorption. The complexing agent arsenazo(III)

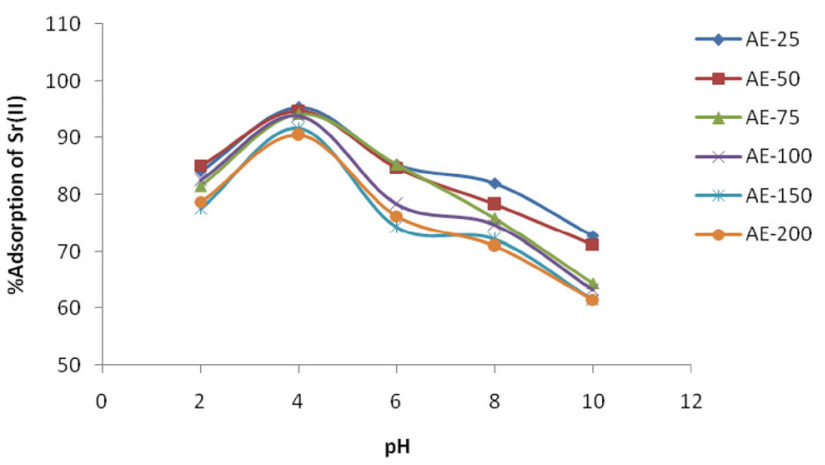

Figure 10. Influence of $\mathrm{pH}$ on $\mathrm{Sr}(\mathrm{II})$ adsorption.

(0.05\%) was prepared by dissolving $50 \mathrm{mg}$ of arsenazo(III) in $100 \mathrm{ml}$ of deionized water.

\subsection{Influence of $\mathrm{pH}$}

The $\mathrm{pH}$ of the solution is the most crucial parameters influencing the adsorption of the metal ion. The optimum $\mathrm{pH}$ conditions for the removal of $\mathrm{Sr}$ (II) sorption were determined using $50 \mathrm{mg}$ of ethylene diamine-modified AGE-EGDMA polymeric beads added to $10 \mathrm{ml}$ of $20 \mathrm{mg} \mathrm{l}^{-1}$ of $\mathrm{Sr}$ (II) solution with $\mathrm{pH}$ ranging from 2 to 10 . The residual concentration of strontium was measured by a spectrophotometer using the arsenazo(III) complexing agent. Figure 10 depicts the influence of $\mathrm{pH}$ on the adsorption of strontium.

The experimental data reveal that the maximum adsorption of $\mathrm{Sr}$ (II) was achieved at $\mathrm{pH} 4$ (95.3\% for AE-25; $94.8 \%$ for AE-50; $94.2 \%$ for AE-75; $93.8 \%$ for AE-100; $91.7 \%$ for 


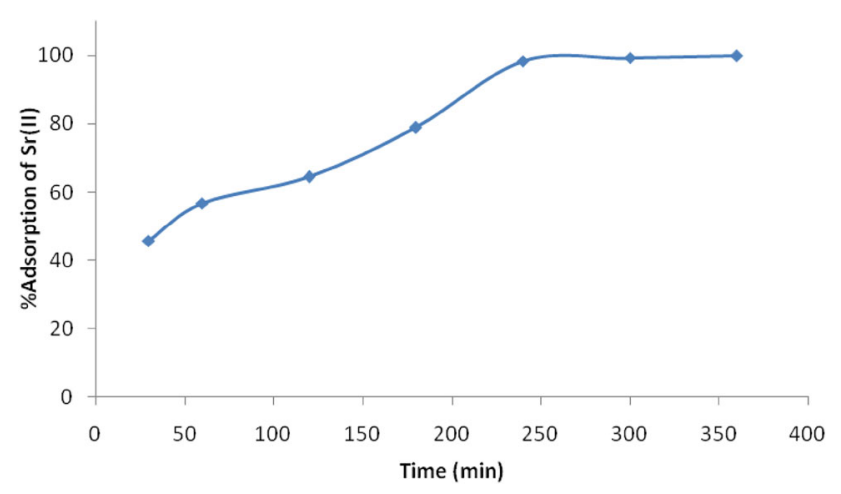

Figure 11. Effect of the contact time on $\mathrm{Sr}$ (II) adsorption.

AE-150 and 90.5\% for AE-200) which indicated that a high affinity of $\mathrm{Sr}(\mathrm{II})$ ions was predominant at $\mathrm{pH} 4$. Almost $88 \%$ of adsorption of the $\mathrm{Sr}$ (II) ion took place at $\mathrm{pH} 2$. The adsorption efficiency of strontium(II) decreases with an increase in $\mathrm{pH} 4-10$. At higher $\mathrm{pH}, \mathrm{Sr}$ (II) adsorption efficiency was comparatively lower due to hydrogen bonding with the polymer [15]. In demineralized water, distribution of strontium species present in the form of $\mathrm{Sr}^{2+}$ at the $\mathrm{pH}$ range 1 to 11 and a very negligible $\mathrm{Sr}(\mathrm{OH})^{+}$species, which increases its concentration above $\mathrm{pH} 10$. Hence, in the range of $\mathrm{pH} 6$ to 8, strontium(II) was found in the form of $\mathrm{Sr}^{2+}$ [16]. At lower $\mathrm{pH}$, the strong acidity replaced the adsorbed $\mathrm{Sr}(\mathrm{II})$ ions by $\mathrm{H}^{+}$, which decreases the adsorption capacity of strontium [17]. Therefore, for further adsorption experiments, $\mathrm{pH} 4$ was selected.

\subsection{Effect of contact time}

The optimum sorption time of $\mathrm{Sr}$ (II) ions was studied by applying the following procedure. Fifty milligrams of chemically modified AGE-EGDMA polymeric beads were shaken with $10 \mathrm{ml}$ of $\mathrm{Sr}$ (II) solution $\left(20 \mathrm{mg} \mathrm{l}^{-1}\right)$ at different sorption times (30, 60, 120, 180, 240 and $360 \mathrm{~min})$ at $\mathrm{pH} 4$. The concentration of $\mathrm{Sr}$ (II) ions in the solution was determined by a spectrophotometer using a recommended procedure. The results obtained from this study are presented in figure 11 .

It can be seen that the adsorption percentage quickly increases with an increase in contact time. This result showed that the adsorption process was rapid. As demonstrated in figure 11, the optimum adsorption contact time was $240 \mathrm{~min}$ and about half of the time for saturation of chemically modified AGE-EGDMA polymeric beads was $<60 \mathrm{~min}$. These data also showed that $\mathrm{Sr}$ (II) uptake on these polymeric beads reflected good accessibility of the sorption site in the polymeric beads. The adsorption time is an important factor that affects the efficiency of strontium ions by the polymeric beads in the aqueous phase. Therefore, an adsorption equilibrium time of $240 \mathrm{~min}$ for polymeric beads was selected and used for all further studies.



Figure 12. Effect of the initial concentration on $\operatorname{Sr}($ II) adsorption.

\subsection{Effect of metal ion concentration}

The effect of metal ion concentration is the second most important factor that affects the metal ion adsorption. The effect of the metal ion concentration on the metal adsorption using polymeric beads was investigated. In this experiment, $50 \mathrm{mg}$ of ethylene diamine modified AGE-EGDMA polymeric beads were added to $20 \mathrm{ml}$ capacity test tubes containing $10 \mathrm{ml}(10,20,30,40,50,60$ and $70 \mathrm{ppm})$ of each metal ion in $\mathrm{pH} 4$ buffer solution. The adsorption of $\mathrm{Sr}(\mathrm{II})$ ions on AGE-EGDMA polymeric beads $(50 \mathrm{mg})$ was tested. The experimental results are shown in figure 12 .

As shown in figure 12, the maximum adsorption was achieved for $10 \mathrm{ppm}$ solution i.e., 99.2\%, whereas only $13.3 \%$ was obtained for the $70 \mathrm{ppm}$ solution. The amount of $\mathrm{Sr}$ (II) adsorption decreases with an increase in the metal ion concentration. The adsorption percentage of $\mathrm{Sr}$ (II) was almost constant for strontium concentration ranging from 50-70 ppm. This was mainly due to the adsorption sites on adsorbents which were occupied by metal ions.

\subsection{Effect of adsorbent dose}

The effect of adsorbent dose was investigated with $40 \mathrm{ppm}$ of $\mathrm{Sr}$ (II) metal ion solution. Ten millilitres of (40 ppm) strontium solution was added to six different $20 \mathrm{ml}$ capacity glass test tubes. To these glass tubes, different amounts of adsorbents $(20,40,60,80,100$ and $120 \mathrm{mg})$ were added and kept aside at room temperature for $4 \mathrm{~h}$. Supernatant layers from each test tube were removed and analysed using a UV spectrometer. The results are presented in figure 13 .

The effect of the amount of AGE-EDMA polymeric beads on the removal of $\mathrm{Sr}$ (II) was investigated. The obtained results showed that the removal efficiency increased with an increase in the amount of adsorbent dose. It was clearly understood that the adsorption capacity of polymeric beads depends on the surface activity. Hence, greater concentration of the adsorbent contained more adsorptive sites. Until now, various kinds of adsorbents have been employed for the removal of strontium from contaminated water. However, the polymersupported 18-crown-6-ether was hardly used for the removal 


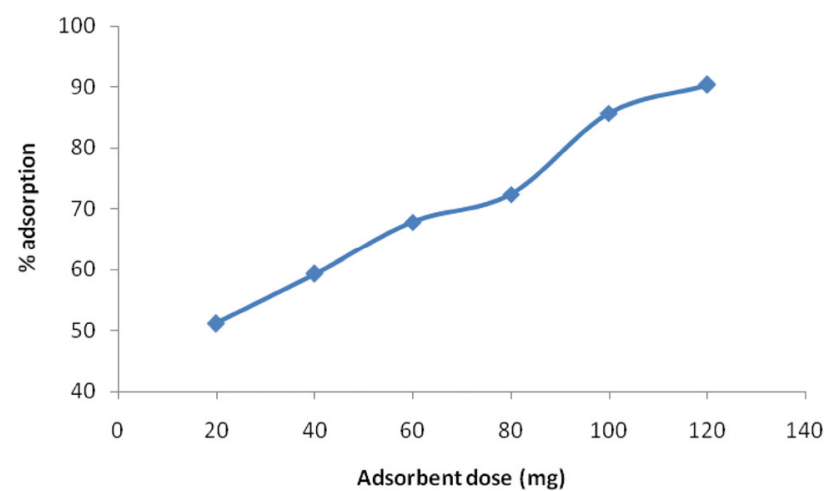

Figure 13. Effect of the adsorbent dose on Sr(II) adsorption.

of strontium from contaminated water. About $90 \%$ of $\mathrm{Sr}(\mathrm{II})$ removal efficiency was achieved using $150 \mathrm{mg}$ of polymersupported 18-crown-6-ether [18].

\subsection{Adsorption kinetics}

Adsorption kinetic models are used to investigate the controlling mechanism of the adsorption process. The kinetic model also describes the rate of the removal of metal ions from the aqueous phase which is one of the most important characteristics that defines the efficiency of adsorption. The efficiency of adsorption is determined using the kinetics of uptake of metal ions by the adsorbent. It is nothing but the study of the rate of metal ions uptake by the adsorbent. The equilibrium is determined by the distribution of a solute between solid-liquid phases and also by determining the feasibility and capacity of the sorbent for adsorption. Currently, a number of kinetic models are used to explain the mechanism of adsorption progress. The pseudo-first-order and pseudosecond-order kinetic models are used to evaluate the kinetic mechanism and also tested to interpret the experimental data. The simplest and widely used Lagergren pseudo-first order equation is given below [19,20].

$$
\log \left(q_{\mathrm{e}}-q_{\mathrm{t}}\right)=\log q_{\mathrm{e}}-\frac{K_{\mathrm{ad}} t}{2.303}
$$

where $q_{\mathrm{e}}$ is the mass of the metal adsorbed at equilibrium $\left(\mathrm{mg} \mathrm{g}^{-1}\right), q_{\mathrm{t}}$ the mass of the metal adsorbed at time $t\left(\mathrm{mg} \mathrm{g}^{-1}\right)$ and $K_{\mathrm{ad}}$ is the first-order reaction constant $\left(1 \mathrm{~min}^{-1}\right)$. The rate constants for the adsorption of strontium ions onto polymeric beads were determined by using the above Lagergren equation. The pseudo-first-order kinetic model considers that the rate of occupation of sorption sites is proportional to the number of unoccupied sites. The rate constant $K_{\text {ad }}$ for the adsorption of chromium on beads was studied by using the initial metal ion concentration, $40 \mathrm{mg} \mathrm{l}^{-1}$, and the results are presented in figure 14. The adsorption rate constant $K_{\text {ad }}$ is calculated from the slope of the above plot. The correlation coefficient $\left(R^{2}\right)$ for the first-order rate constant is 0.876 .



Figure 14. Pseudo-first-order kinetic plot for Sr(II) adsorption.

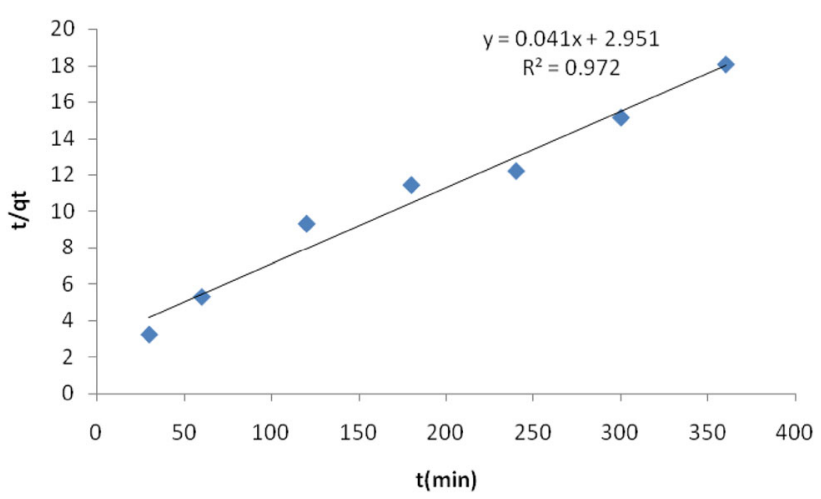

Figure 15. Pseudo-second-order kinetic plot for $\mathrm{Sr}(\mathrm{II})$ adsorption.

For the adsorption system, pseudo-second order kinetic expression is developed by Ho [21]. It assumes that the adsorption rate is controlled by chemical adsorption. The pseudo-second order rate equation describes equilibrium capacity. It depends on the concentration of either first-order reactants or second-order reactant. The pseudo-second order rate equation is presented as follows:

$$
\frac{t}{q_{\mathrm{t}}}=\frac{1}{K_{2 \mathrm{ad}} q_{\mathrm{e}}^{2}}+\frac{t}{q_{\mathrm{e}}},
$$

where $K_{2 \mathrm{ad}}$ is the second-order reaction rate equilibrium constant $\left(\mathrm{g} \mathrm{mg}^{-1} \cdot \mathrm{min}^{-1}\right)$ for the adsorption of $\mathrm{Sr}(\mathrm{II})$ on beads with a concentration of $40 \mathrm{mg}^{-1}$. The kinetic plot of $t / q_{\mathrm{t}} v s . t$ for the adsorption of $\mathrm{Sr}(\mathrm{II})$ is shown in figure 15. As shown in figure 15 , a plot of $t / q_{\mathrm{t}} v s$. $t$ provides a good straight line and gives a linear relationship for the applicability of the secondorder kinetic model. The second-order rate constant $K_{2 \text { ad }}$ was calculated from the graph. The correlation coefficient $\left(R^{2}\right)$ for the second-order rate constant was 0.972 indicating that the results were fitted well with the pseudo-second-order kinetic model.

The mechanism of adsorption process is investigated by applying the intra-particle diffusion kinetic model [22] (equation (3)) and the result is shown in figure 16. 




Figure 16. Intra-particle diffusion kinetic model.

$$
q=K_{\mathrm{i}} t+C,
$$

where $C$ is the intercept and $K_{\mathrm{i}}$ the intra-particle diffusion rate constant ( $\mathrm{mg} \mathrm{g}^{-1} \mathrm{~min}^{-1 / 2}$ ). It can be evaluated from the slope of the linear plot of $q$ vs. $t^{1 / 2}$. When comparing the regression coefficients, the first-order rate expression and intra-particle diffusion model were not fully valid for the present system. However, a good agreement of experimental data with the second-order kinetic model was observed.

\section{Conclusions}

In conclusion, resorcin[4] arene-functionalized macroporous poly(AGE-co-EGDMA) beads were successfully synthesized. These macroporous beads were used for the adsorptive removal of strontium(II) from the aqueous phase. The batch experiments were performed at $\mathrm{pH}$ ranging from $2-10$. The effects of parameters such as $\mathrm{pH}$, contact time, adsorbent dose and initial metal ion concentration were tested. The result showed that the maximum adsorption affinity (about 99\%) was observed at $\mathrm{pH} 4$ by functionalized macroporous poly(AGE-co-EGDMA), the optimum conditions for $50 \mathrm{mg}$ of functionalized beads and $20 \mathrm{ppm} \mathrm{Sr}$ (II) were solution of $\mathrm{pH} 4$ and adsorption time of $4 \mathrm{~h}$ at room temperature. The adsorption kinetic models, pseudo-first-order and pseudosecond-order kinetics were analysed. The correlation coefficient $\left(R^{2}\right)$ for pseudo-first-order and pseudo-second-order kinetics was found to be 0.876 and 0.972 , respectively. We propose that this resorcin[4]arene-functionalized macroporous poly(AGE-co-EGDMA) beads can effectively remove strontium ions from contaminated water.

\section{References}

[1] NLM. Rickets. Available from: http://www.nlm.nih.gov/ medlineplus/ency/article/000344.htm. Accessed on 8th Jan 2018

[2] Mariangela G, Kaykioglu G, Belgiorno V and Lofrano G 2012 Removal of emerging contaminants from water and wastewater by adsorption process. In emerging compounds removal from wastewater natural and solar based treatments (Salerno: Springer) p 15

[3] Nwafulugo F U, Adefila S S, Olawale A S and Ajayi O A 2014 J. Environ. Sci. Water Res. 3132

[4] Wang J and Chen C 2009 Biotech. Advan. 27195

[5] Won W, Kotte P, Wei A and Yeoung-Sang Y 2014 Biores. Tech. 160203

[6] Liu C, Bai R and Hong L 2006 J. Colloid. Interface Sci. 303 99

[7] Liu Q, Xia B, Huang J, Liao J, Liu H, Ou B et al 2017 Mater. Chem. Phys. 199616

[8] Liu Q, Li G, Tang Z, Chen L, Liao B, Ou B et al 2017 Mater. Chem. Phys. 18611

[9] Duran A, Solak M and Tunel S A 2008 J. Hazard. Mater. 155 114

[10] Joanna K and Grzegorz S 2013 Cent. Eur. J. Chem. 111723

[11] Frechet J M 1993 J. Macromol. Chem. Macromol. Symp. 70 289

[12] Hoegberg A 1980 J. Org. Chem. 454498

[13] Matsushita Y and Matsui T 1993 Tetra. Lett. 347433

[14] Agrawal Y K and Jain R K 1979 J. Chem. Eng. Data 24250

[15] Rongjian Y 2015 Inter. J. Anal. Chem. Article ID 4250841

[16] Yavari R, Huang Y D and Mostofizadeh A 2010 J. Radioanal. Nucl. Chem. 285703

[17] Wang M, Xu L, Peng J, Zhai M, Li J and Wei G 2009 J. Hazard. Mater. 171820

[18] Mane S T, Ponrathnam S and Chavan N N 2016 J. Appl. Polym. Sci. 42849

[19] Lagergren S 1898 Handlingar 241

[20] Aksu Z 2002 Process. Biochem. 3889

[21] Ho Y S and McKay G 1998 Adsorpt. Sci. Technol. 16243

[22] Namasivayam C and Ranganathan K 1993 Environ. Poll. 82 255 